\title{
Effect of long term supplementation of active garlic allicin in reducing blood pressure in hypertensive subjects
}

\author{
Kshitij Bhardwaj $^{1 *}$, Manish Kumar Verma², Narsingh Verma ${ }^{3}$, Shipra Bhardwaj ${ }^{3}$, \\ Saumya Mishra ${ }^{3}$
}

\begin{abstract}
${ }^{1}$ Department of Chemical Technology, Harcourt Butler Technological Institute, Kanpur, India
${ }^{2}$ Department of Physiology, Hind Institute of Medical Sciences, Safedabad Barabanki, UP, India

${ }^{3}$ Department of Physiology, King George Medical University, Lucknow, India
\end{abstract}

Received: 13 June 2015

Accepted: 11 July 2015

*Correspondence:

Dr. Kshitij Bhardwaj,

E-mail: kbhardwaj3@gmail.com

Copyright: (C) the author(s), publisher and licensee Medip Academy. This is an open-access article distributed under the terms of the Creative Commons Attribution Non-Commercial License, which permits unrestricted non-commercial use, distribution, and reproduction in any medium, provided the original work is properly cited.

\begin{abstract}
Background: Researchers all over the world have independently shown the effect of allicin in reducing blood pressure depends on its extraction and concentration. Among the active constituents in garlic, the principal component is allicin. It is not present in the intact garlic clove but is produced together with pyruvate and ammonia from the odourless precursor alliin (S-allyl-L-cysteine sulfoxide) in the presence of the enzyme alliinase; Allin and allinase are found in different compartments of the garlic clove and are brought into contact to produce allicin only by cutting or crushing the clove. If garlic is processed and extracted, using oil, the activity of the sulphur compounds is sealed which could not be readily used by the body. Study aim to use pure raw and active form of sulphur from garlic and observe the effect of associated allicin on hypertensive subjects.

Methods: Extracted active sulphur chemicals and allicin from garlic by crushing fresh garlic cloves using water as extracting medium. Raw crushed $25 \mathrm{gm}$. garlic clove with water was given twice daily to 100 hypertensive subjects, 60 males and 40 females of 30-55 years of age for the period of six months. Health records of each subjects was individually maintained. Blood pressure was measured initially, after three months and finally after six months. Statistically comparison was made between initial, three months and six months blood pressure data of the subjects.

Results: This simple extraction method produce allicin yield of $100 \%$, which reduced up to $10 \%(5 \mathrm{mmHg}) \mathrm{systolic}$ and diastolic Blood pressure in subjects who were supplemented with garlic-allicin paste.

Conclusions: Extraction quality and activity of allicin is dependent of mode of processing and extraction medium. Garlic is a basic food that augments the body health and lowers blood pressure as well as blood cholesterol. Garlic is an ideal herb for several cardiovascular supplements. It would be of value to further examine these effects of allicin in humans with hypertension. Future research will enable in vivo measurement of allicin and its pharmacological properties; physiological effects and mechanisms of action should be investigated further.
\end{abstract}

Keywords: Garlic, Allicin, Hypertension, Cardiovascular system, Blood pressure

\section{INTRODUCTION}

Several studies have shown that garlic has a beneficial effect on cardiovascular risk factors such as dyslipidemia, high blood pressure and glucose levels. In addition, it has an antioxidative effect, an antiplatelet aggregation effect, and enhances fibrinolytic activity. ${ }^{1-4}$ Various studies on management of hypertension suggest that by reducing diastolic, blood pressure as little as $5 \mathrm{~mm}$ of $\mathrm{Hg}$ would decrease the risk of developing coronary heart disease by a massive 16 per cent. $^{2}$ Allicin, a sulfur-containing natural compound with many different biological 
properties is responsible for the typical smell and taste of freshly cut or crushed garlic. ${ }^{5,6}$ Allicin is known to significantly reduce both systolic and diastolic blood pressure. Data from these studies point to the possible role of garlic in the prevention and control of cardiovascular risk factors. However, the results are inconsistent and some studies show conflicting results probably due to methodological differences. ${ }^{7,8}$ The main challenge has been the isolation and process of preparing a stable form of the active compound in garlic and determining its concentration. In addition, differences in patient selection, randomization, blinding and insufficient data regarding the effective dose also account for the inconsistent results. The principal component of garlic is allicin (thio-2-propene-1-sulfinic acid S-allyl ester). ${ }^{1}$ It is not present as such in the intact garlic clove but is produced together with pyruvate and ammonia from the odourless precursor alliin (+) (S-allyl-L-cysteine sulfoxide) in the presence of the enzyme alliinase. ${ }^{9}$ Alliin and alliinase are found in different compartments of the garlic clove and are brought into contact to produce allicin by cutting or crushing the clove. ${ }^{6}$ The latter is a chemically unstable, colourless liquid that is thought to be responsible for both the odour and much of the biological activity of garlic. The method of extracting active sulfur chemicals from garlic is also very important. $^{20}$ Researchers all over the world have independently shown that when garlic is processed and extracted, using oil, it seals up the activity of the sulfur compounds so they will not be readily used by the body. ${ }^{12}$ Water-based extracts (like real allicin) are much more active. ${ }^{13}$ Natural fresh raw garlic cloves to investigate effect on both systolic and diastolic blood pressure.

\section{METHODS}

\section{Preparation of allicin:}

Active sulphur chemicals and allicin from garlic by crushing fresh garlic cloves using small amount fresh water as an extracting medium. Subjects were supplemented with 25 grams crushed garlic cloves.

\section{Selection of subjects:}

\section{Inclusion criteria:}

100 Subjects 60 males and 40 female of 25-55 year of age were selected from the OPD of medicine department of Hind Medical College Lucknow India. Informed consent was obtained and only drug naive subjects having blood pressure systolic in range of more than 140 and less than $150 \mathrm{~mm}$ of hg and Diastolic blood pressure less than $95 \mathrm{~mm}$ of $\mathrm{Hg}$ were selected.

\section{Exclusion criteria:}

1. Known Hypertensive on drug

2. Hypertension with Known CAD

3. Secondary Hypertension

\section{Oral administration of allicin to hypertensive patient:}

Raw crushed (2) average sized garlic clove with water was given daily twice to 100 Subjects 60 males and 40 female of 30-55 year of age subjects (Casual BP $\leq$ 129/89) for 3 and 6 months period. BP and health records of each subjects was individually maintained.

\section{Statistical Analysis:}

Statistical analysis was done by using Analysis of Variance (ANOVA).

\section{RESULTS}

The blood pressure of the patients receiving crushed garlic cloves on non-controlled diet was significantly lower $(\mathrm{p}<0.05, \mathrm{p}<0.01)$ at a same time i.e. 6 pm over a period of 3 and 6 month. Systolic blood pressure which was initially recorded $145.5 \pm 4.30 \mathrm{mmHg}$ decreased to $141.31 \pm 6.35 \mathrm{mmHg}$ and then to $137.14 \pm 6.31 \mathrm{mmHg}$. Similarly initial diastolic blood pressure was noted 91.88 $\pm 5.77 \mathrm{mmHg}$, after three months it decreased to $89.66 \pm$ 0.16 which finally reduced to $87.48 \pm 6.18 \mathrm{mmHg}$. However there was a gradual $10 \%$ decrease in diastolic and systolic blood pressure over a significant period of time (Figure 1\& 2).

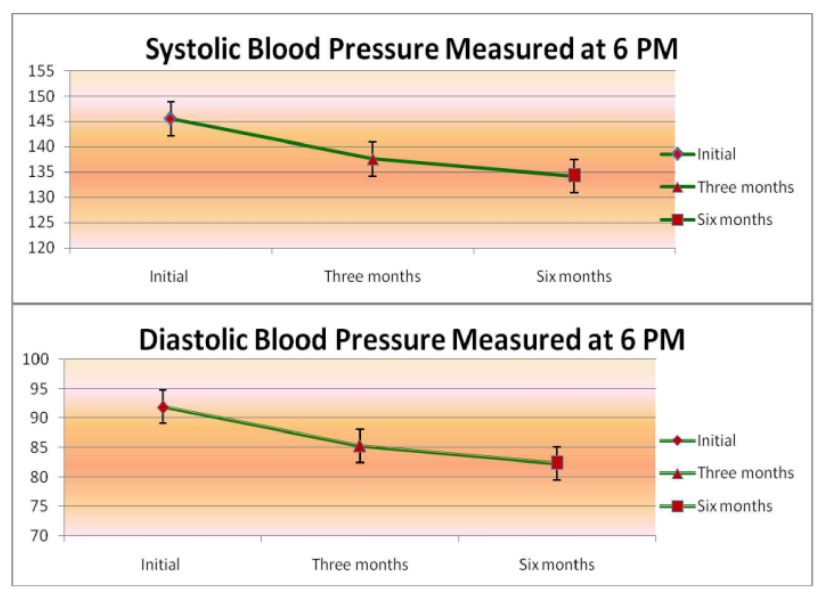

Figure 1: Effect of garlic allicin extract on mean blood pressure of 100 subjects at $6 \mathrm{pm}$ after 3 month and 6 month.

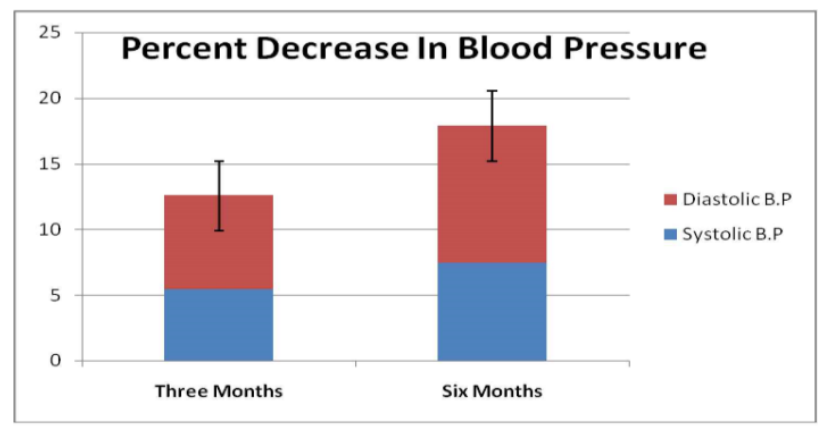

Figure 2: Percent decrease in blood pressure after allicin supplementation. 


\section{DISCUSSION}

Allicin action on cardiovascular risk markers is not fully understood, ${ }^{13,14,15}$ it have broad range of biological activities and is produced from the non-proteinogenic amino acid alliin ( $\mathrm{S}$-allylcysteine sulfoxide) in a reaction that is catalyzed by the enzyme alliinase. Being a thiosulfinate, allicin is reactive sulfur species (RSS) and undergoes a redox-reaction with thiol groups in glutathione and proteins ${ }^{16,17}$ that is thought to be essential for its biological activity because of which allicin have various health protecting properties like cholesterol and blood pressure-lowering effects. Allicin action on cardiovascular risk markers is not fully understood, however, it does appear to act as a vasodilator. Studies suggest that allicin may exert ability to lower blood pressure by acting like prostaglandin E1, which decreases peripheral vascular resistance. ${ }^{14}$ What is clear is that to get any significant effect. The active ingredient allicin must reach to the site of action. ${ }^{16,17}$ Most garlic preparations are not able to provide any allicin in its active form consequently they have not shown any benefit. ${ }^{18}$ This study tried to understand the effect of raw crushed garlic which is supposed to be a big source of allicin.

\section{CONCLUSION}

Extraction quantity and activity of allicin is dependent of mode of extraction medium. There is significant change in both systolic and diastolic blood pressure by using raw garlic. Therefore study suggests that raw garlic naturally. Future research will enable in vivo measurement of naturally extracted allicin and its pharmacological properties, physiological effects and mechanisms of action should be investigated further.

\section{ACKNOWLEDGEMENTS}

The authors are grateful to the Hind medical college Lucknow for patient recruitment and King George medical university for Technical and statistical help.

\section{Funding: No funding sources}

Conflict of interest: None declared

Ethical approval: The study was approved by the institutional ethics committee

\section{REFERENCES}

1. Elkayam A, Peleg E, Grossman E, Shabtay Z, Sharabi Y. Effects of Allicin on Cardiovascular Risk Factors in Spontaneously Hypertensive Rats, Isr Med Assoc J. 2013;15(3):170-3.

2. Agarwal KC. Therapeutic actions of garlic constituents. Med Res Rev 1996;16:111-24.

3. Berthold HK, Sudhop T, and von Bergmann K. Effect of a garlic oil preparation on serum lipoproteins and cholesterol metabolism: a randomized controlled trial. JAMA. 1998;279:19002.

4. Gadkari JV, Joshi VD. Effect of ingestion of raw garlic on serum cholesterol level, clotting time and fibrinolytic activity in normal subjects. J Postgrad Med. 1991;37:128-31.

5. Harenberg J, Giese C, Zimmermann R. Effect of dried garlic on blood coagulation, fibrinolysis, platelet aggregation and serum cholesterol levels in patients with hyperlipoproteinemia. Atherosclerosis. 1988;74:247-9.

6. Lawson LD, Ransom DK, Hughes BG. Inhibition of whole blood platelet aggregation by compounds in garlic clove extracts and commercial garlic products. Thromb Res. 1992;65:141-56.

7. Neil A, Silagy C. Garlic: its cardio-protective properties. Curr Opin Lipidol. 1994;5:6-10.

8. Warshafsky S, Kamer RS, Sivak SL. Effect of garlic on total serum cholesterol. A meta-analysis. Ann Intern Med. 1993;119:599-605.

9. Freeman F, Kodera Y. Garlic chemistry: stability of (S)-(2-propenyl) 2-propene-1 sulfinothioate (Allicin) in blood, solvents, and simulated physiological fluids, Journal of Agricultural and Food Chemistry. 1995;43(9):2332-8.

10. Cavallito CJ, Bailey JH. Allicin, the antibacterial principle of Allium sativum. Isolation, physical properties and antibacterial action, Journal of the American Chemical Society. 1944;66(11):1950-1.

11. Antithrombotic organosulfur compounds from garlic: structural, mechanistic and synthetic studies, Journal of the American Chemical Society. 1986;108(22):7045-55.

12. Block E, Ahmad S, Catalfamo JL, Jain MK, ApitzCastro R. The chemistry of alkyl thiosulfinate esters. Antithrombotic organosulfur compounds from garlic: structural, mechanistic and synthetic studies, Journal of the American Chemical Society. 1986;108(22):7045-55.

13. Koch HP, Lawson LD. Garlic: The Science and Therapeutic Application of Allium sativum L. and Related Species 2nd Ed: 329 William and Wilkins Baltimore, MD, 1996.

14. Neil A, Silagy C. Garlic: its cardio-protective properties. Curr Opin Lipidol 1994;5:6-10.

15. Yin Lu, Zhuojin He, Xiuying Shen, Xiaolu Xu, Jie Fan, Shaohua Wu and Deyong Zhang. CholesterolLowering Effect of Allicin on Hypercholesterolemic ICR Mice Oxidative Medicine and Cellular Longevity Volume 2012, Article ID 489690, 6 pages.

16. Block, E. Garlic and Other Alliums-the Lore and The Science; RSC publishing: Cambridge, UK, 2010.

17. Jan Borlinghaus, Frank Albrecht, Martin C. H. Gruhlke, Ifeanyi D. Nwachukwu and Alan J. 
Slusarenko; Allicin: Chemistry and Biological Properties, Molecules 2014, 19, 12591-12618.

18. Ilić D, Nikolić V, Nikolić L, Stanković M, Stanojević L, Cakić M. Allicin and relatedcompounds: Biosynthesis, synthesis and pharmacological activity. Facta Univ. Phys. Chem. Technol. 2011, 9, 9-20.
Cite this article as: Bhardwaj K, Verma MK, Verma $\mathrm{N}$, Bhardwaj S, Mishra S. Effect of long term supplementation of active garlic allicin in reducing blood pressure in hypertensive subjects. Int J Adv Med 2015;2:231-4. 